Differences in Functional and Aesthetic Body Image between Sedentary Girls and Girls Involved in Sports and Physical Activity: Does Sport Type Make a Difference?

\author{
Bree, D. Abbott ${ }^{1}$ \\ Bonnie, L. Barber ${ }^{2}$
}

\footnotetext{
${ }^{1}$ Murdoch University, School of Psychology, South Street, Murdoch, Western Australia, 6150. Email: b.abbott@ murdoch.edu.au, Phone: +61 08 93607314, Fax +61 0893606492

${ }^{2}$ Murdoch University, School of Psychology, Perth, Western Australia
} 


\section{Differences in Functional and Aesthetic Body Image between Sedentary Girls and Girls Involved in Sports and Physical Activity: Does Sport Type Make a Difference?}

During adolescence the body becomes a central focus as it develops from child to adult and as a result body image is a major concern for many adolescents. A study conducted by Mission Australia (2008) highlights the level of importance that body image has in the everyday lives of Australian adolescents. The study surveyed more than 45,000 young Australians aged 11-24, and found that the top three greatest concerns reported by young people were body image, family conflict and coping with stress, respectively. One in four young Australian females reported body image as their biggest worry and although body dissatisfaction is not distinctively a female issue, female adolescents consistently report greater body dissatisfaction than do adolescent males (Barker \& Galambos, 2003; Cash, Fleming, Alindogan, Steadman \& Whitehead, 2002; Gadbois \& Bowker, 2007), and it is during adolescence that these gender differences become more apparent (Rosenblum \& Lewis, 1999).

Body image is an important factor in adolescents' well-being and a negative body image has been associated with poor self-esteem (Clay, Vignoles \& Dittmar, 2005; Davison \& McCabe, 2006; Franzoi \& Shields, 1984; Furnham, Badmin, \& Sneade, 2002), depression (Noles, Cash \& Winstead, 1985; Rierdan \& Koff, 1997; Rierdan, Koff \& Stubbs, 1989), and disordered eating (Cash \& Deagle, 1997; Rieder \& Ruderman, 2001). Therefore it is important to try to understand what factors are related to a positive body image in adolescents, particularly among females. The current study explores the sporting context as an environment that may promote a positive body image among this population; however body image, as it is measured in the current study, must first be defined. 


\section{Body Image: Form and Function}

The current research defines body image as the perceptions individuals hold towards their bodies, consisting of affective/evaluative, cognitive, and behavioral components, thus rendering body image a multi-dimensional construct (Brown, Cash \& Milulka, 1990; Cash, Melnyk \& Hrabosky, 2004). That is, body image is constructed through the value individuals place on different aspects of their bodies, the behavioral-investment made to maintain these aspects and the affective evaluations made regarding their satisfaction with their bodies (Author citation deleted, 2010). Although the body may be widely evaluated for its form or appearance, it may also be used as an instrument to interact with, explore and experience the world. It may therefore be suggested that the body not only has aesthetic qualities, but also has instrumental or functional qualities. Thus, in the current research, body image is not confined to perceptions of physical attractiveness, or the way the body "looks"; it also extends to perceptions of how the body feels, moves and functions, or what the body can “do."

The instrumental or functional qualities of the body can be overlooked in body image research; however these qualities may also influence the perceptions that people have of their bodies. A sense of physical competence has been associated with positive feelings towards the body (Greenleaf, Boyer \& Petrie, 2009) and a focus on body function has also been associated with greater body appreciation and intuitive eating (Avalos \& Tylka, 2006). In addition, research distinguishing between the aesthetic body and the functional body has found that the functional body is evaluated more positively than the aesthetic body (Author citation deleted; Franzoi, 1995). Females, in particular, tend to evaluate the aesthetic qualities of their bodies more negatively than the functional qualities, and express a greater desire to change these aesthetic aspects of their bodies than do males (Franzoi, 1995; Gusella, Clark \& van Roosmalen, 2004). However, when the body is viewed through a functional lens, girls 
make fewer negative evaluations of their bodies, and express lower body dissatisfaction (Gusella et al., 2004).

Having an objectified view of the body, or focusing primarily on the aesthetic qualities of the body, encourages girls to view their bodies from an outside observer's perspective (Frederickson \& Roberts, 1997). An aesthetic focus has been associated with body shame, anxiety, lower body esteem, body dissatisfaction, and poor interoceptive awareness (Frederickson \& Roberts, 1997; McKinley, 1998; McKinley \& Hyde, 1996; Strelan, Mehaffey \& Tiggemann, 2003; Tylka \& Hill, 2004). However, focusing on the body's functional qualities may encourage girls to incorporate bodily experiences (such as physical competence) rather than taking purely an observer's perspective when making evaluative judgments about the body. The current study therefore examines both the functional and aesthetic dimensions of body image, investigating the values, behavioral investment, and satisfaction associated with each dimension. Adopting this perspective may be useful in identifying contexts that have the potential to facilitate a functional body image and aid in the dilution of body objectification and the immense focus on appearance that Western adolescent females are presented with. Sports Participation and Body Image

It may be argued that sports programs have the potential to encourage an identity and body image that incorporates physical skill and potential, rather than being solely based on physical appearance and sexuality (Brady, 2005; 1998). A major key to enhancing functional views of the body among females is through experiential learning (Scott \& Derry, 2005). Physical activity and sports offer girls an opportunity to experience freedom of movement and to invest in the instrumental qualities and potential of their bodies (Kitchen, 2006), with physical ability judged to be more important by athletes than non-athletes (Marsh \& Jackson, 1986). Sports increase awareness of the body's physical capabilities (Jaffe \& Manzer, 1992; 
Jaffe \& Ricker, 1993; Williams \& Cash, 2001) and give girls an opportunity to not only experience, but also improve, their bodily strength, agility, flexibility, speed, endurance, coordination, and power, giving them a sense of physical competence (Burgess, Grogan \& Burwitz, 2006; Ference \& Muth, 2004; Marsh \& Jackson, 1986). As a result, sports participants may invest in their bodies' physicality, adopt functionally-based body values, and incorporate these values and experiences when making evaluative judgements about their bodies. It is not suggested that these functionally focused values will replace appearancebased values, but that they will be integrated into girls' body image and create a blend between function and form.

Sport types. Although participation in sporting activities has been positively associated with body image, these findings are not always consistent (Hausenblas \& Symons Downs, 2001), specifically when examinations into different sport types have been made (Smolak, Murnen, \& Ruble, 2000). Participants in aesthetically-based sports, or sports emphasizing the body's physical appearance (such as dance and gymnastics), report high drive for thinness (Slater \& Tiggemann, in press), self-objectification, body surveillance (Tiggemann \& Slater, 2001), body shame (Parsons \& Betz, 2001), and disordered eating behaviors (Smolak et al., 2000). Thus, aesthetically focused sports may accentuate one's awareness of observers' perspectives and the need to adhere to body ideals, and is associated with girls placing less emphasis or value on physical competence or function and more emphasis on appearance. In addition, participation in aesthetic sports is associated with monitoring and investing in the body's appearance more than its physicality as well as a sense of shame or guilt when an appearance ideal is not achieved (Parsons \& Betz, 2001; Tiggemann \& Slater, 2001). Few research projects have compared the relative expereinces of aesthetic and functional body image between aesthetic and non-aesthetic sports activities. In addition, due to the inconsistencies found between the influence of sports on body image, 
further research is required into the relationship between participation in difference sport types and both aesthetic and functional body image.

Physical activity. It may be argued that sporting contexts are not unique in their potential to provide girls with opportunities to experience and improve the body's physicality. General physical activity (for example aerobic programs, circuit training) has been associated with positive appearance and health/fitness evaluations (Henry, Anshel, \& Michael, 2006) and may also provide girls with similar opportunities to invest in the body functionally (Parsons \& Betz, 2001). However, this type of activity is often undertaken as a quest to improve appearance (Furnham et al., 2002) and may not solely encourage girls to value their body's functionality. Although a sense of athletic competence has been associated with participation in team sports, no such relation was found for participation in general physical activity (Ference \& Muth, 2004). Additionally, girls involved in team sports report a more positive body image than girls who engage in general physical activity (Jaffe \& Lutter, 1995). As further evidence of this distinction between team sports and general physical activity, exercising in fitness center environments has been associated with selfobjectification, negative body esteem (Pritchard \& Tiggemann, 2008), drive for thinness, and appearance anxiety (Slater \& Tiggemann, in press) and non-sports physical activity has been associated with high body shame (Parsons \& Betz, 2001). It is therefore important that both aesthetic and functional body image comparisons be made between the sporting context and general physical activity in order to explore this theoretical distinction further.

\section{The Current Study}

The aim of the current study was to explore the association between sports participation and body image among Australian adolescent girls. The current study investigated both aesthetic and functional aspects of body image across sport types (aesthetic and non-aesthetic sports) and physical activity. First, the aesthetic and functional body image 
of girls involved in sports activities was compared with those of the girls who were either solely physically active (not in team sports), or sedentary. Aesthetic and functional body image was then examined among girls participating in different sport types. Comparisons were made between girls participating exclusively in aesthetic sports or non-aesthetic sports and those involved in both types of sports.

Hypotheses. The current study has several hypotheses. In comparison to being sedentary, participation in sports and physical activity is expected to promote higher awareness of the functional body. It was therefore hypothesised that compared to nonphysically active girls, those involved in sports or in physical activity will hold a higher functional body image, and will report (1a) Higher value in the functional aspects of the body; (1b) more behavioral-investment in their body's functionality; and (1c) higher satisfaction with both their functional and aesthetic body. However, in line with previous research findings where physical activity participants reported lower perceived competence in athletic abilities (Ference \& Muth, 2004) and poorer body image (Jaffe \& Lutter, 1995) than sport participants, it was hypothesised that $(1 d)$ sports participants would report higher functional and aesthetic satisfaction than would physical activity participants.

We expected that the type of sport girls were involved in could contribute differently to body image. Specifically, due to their focus on the aesthetic qualities of the body, in comparison to participation in non-aesthetic sports, participation exclusively in aesthetic sports was hypothesised to be associated with (2a) Higher aesthetic value and behavioralinvestment; (2b) lower functional value and behavioural-investment; and (2c) lower satisfaction in both the functional and aesthetic body dimensions.

It was unclear how participation in a combination of aesthetic and non-aesthetic sports would relate to body image; therefore no directional hypotheses were made. However, body image is a complex construct and may be negatively influenced by many factors such age 
(Rosenblum \& Lewis, 1999), Body Mass Index (BMI; Paxton, Eisenberg \& NeumarkSztainer, 2006) and pubertal timing (Muth \& Cash, 1997; Stice \& Whitenton, 2002; Thompson \& Chad, 2000). Therefore, before body image comparisons could be made between groups, age, BMI, and pubertal timing were explored as potential covariates.

\section{Method}

\section{Participants}

The current sample was drawn from wave 2 of the Youth Activity Participation Study of Western Australia (YAPS-WA; author citation deleted) collected between July and December of 2008. YAPS-WA is focused on links between adolescents' positive development and the activities filling their leisure time and includes data on a range of indicators of well-being (e.g., risk behavior, school attachment and body image), as well as positive youth experiences, leisure time use, physical development including body mass index (BMI) and pubertal timing, and demographic information. The current study utilized the data pertaining to body image, sports participation, BMI and pubertal timing.

Participants were drawn from 34 metropolitan and rural high schools (19 public government schools and 15 private schools) across the state of Western Australia (12 rural schools and 22 metropolitan schools). All year 9 and 11 students were invited to participate in the study. Overall, 1,837 adolescents (mean age $=14.7, S D=1.10$ ) gained parental consent and responded to the YAPS-WA survey in 2008, 822 of whom were male and 1,002 female (13 participants did not specify gender). The current study focused on the responses of the female participants only. Female participants were between 13 and 18 years of age, with a mean age of $14.6(S D=1.08) ; 65 \%$ were completing grade 9 at the time of data collection and $35 \%$ were completing grade 11 . Eighty-two percent of the sample classified themselves as Caucasian, 7\% as Asian, 2\% as Aboriginal or Torres Strait Islander and 9\% as other (e.g., Middle Eastern, African, Indian, and Maori). 


\section{Measures}

Demographic Variables: Demographic information was collected by asking participants' gender, age and the grade they were currently completing in school. Participants self-reported their ethnicity by selecting from a list of 5 ethnicities (Caucasian, Aboriginal or Torres Strait Islander, Asian, Middle Eastern, African) the one that they felt best described their family background. An additional 'other' option was made available for participants whose ethnicity was not listed. Participants who selected the other option were also asked to specify their ethnicity.

Body Mass Index and Pubertal Timing. Participants' self-reported height (cm) and weight $(\mathrm{kg})$ were also collected to calculate BMI using the equation weight $(\mathrm{kg}) / \mathrm{height}\left(\mathrm{m}^{2}\right)$. Both wall height charts and bathroom scales were made available to all participants to use if they were unsure of their height or weight. Eighty-eight percent $(n=880)$ of the participants gave adequate data to calculate BMI. Participants' BMI ranged from 9 to 62 with a mean BMI of $20.7(S D=3.84)$. However, $12 \%(n=122)$ of the sample did not provide adequate data to calculate BMI. Of these participants, 56 did not provide weight data, 26 did not provide height data, and 40 did not provide any data on weight or height.

Participants' relative pubertal timing was assessed by asking participants to rate, on a 5 -point Likert scale, their physical development in comparison to other people their age $(1=$ much later, 3 = around the same, $5=$ much earlier). For participants who provided data on pubertal timing $(N=884), 4 \%$ perceived they began their physical development "much later," $20 \%$ as "a little later," $51 \%$ as "around the same," $19 \%$ as "a little earlier," and 6\% as "much earlier" than their peers. Only $2 \%(n=19)$ of the sample did not provide relative pubertal timing data.

Sports Participation: Participants were given a list of 14 in-school sports and 23 outof-school sports (see Appendix A) common in Western Australia (Abbott \& Barber, 2007). 
Participants were asked to select each organized sport in which they had participated during the current school year. Sports participation was defined to participants as their involvement in an organized sport (such as a school team or community club/institution). Participants were instructed that sports participation did not include their involvement in physical education classes (as a part of the school curriculum) during school hours nor did it involve unstructured sports involvement (such as a basketball game among friends). To control for the seasonal nature of sports (summer vs. winter sports), participants were given a "not currently active" option which they were instructed to select if they had participated in a particular sport in the past year which was no longer in season or with which they were no longer involved. The total number of sports selected was used as a total sports breadth score; a current breadth score was calculated by subtracting the number of "not currently active" sports from the total breadth score. To measure sport participation intensity, participants were asked how many hours per week (ranging from 1-25 hours) they participated in each sport, and only those sports in which participants were currently active were included in the intensity score.

Physical Activity. Participants were also asked whether they currently participated in any other form of physical activity (either on their own or at the gym, but not including organized sports). If participants reported participating in physical activity they were then asked to specify the type of physical activity in which they participated (for example, going to the gym, walking, jogging, playing non-organized sport with friends). In addition to this specification, participants were also asked how many hours per week they participated in general physical activity.

Participation Portfolios. In order for comparisons to be made between general physical activity and sports participation (including sport types) two portfolios were created. Physical activity portfolios were created to test for body image differences between 
participants who were involved in sports, participants who were physically active and participants who were sedentary. Participants were categorized as either sports participants (79\%, $n=791)$, physically active only $(13 \%, n=130)$, or not physically active $(8 \%, n=81)$. Sports participants were those who reported participating in a school-based or communitybased sport, or both. Physically active only participants were those who did not participate in any organized sports activities but did report spending one or more hours per week in general physical activity (for example; exercise, gym, unstructured sports with friends). Participants classified as not physically active were those who did not report participating in any schoolbased or community-based sports, nor did they report participating any form of physical activity during their leisure time.

A second portfolio variable was created to investigate the sporting context and the possible differences in body image between girls involved in different sport types. Nonaesthetic sports refer to those sports where the physical capabilities of the body (for example; speed, strength, skill) are of central concern in the competitor's sports success. Alternatively, aesthetic sports include those where in addition to the body's physical competence, the aesthetic qualities of the body are also a central factor in a competitor's success in the sport (for example, body lines, appearance, body shape). Sports classed as aesthetic were dance, gymnastics, cheerleading, acrobatics, and aerobics team.

Each participant was categorized as an aesthetic sports only participant, a nonaesthetic sports only participant, a hybrid (aesthetic and non-aesthetic ) participant or a nonparticipant. A participant who reported participating in an aesthetic sport and did not report participating in any non-aesthetic sport they was classified as an aesthetic sports only participant. Non-aesthetic sports only participants were those girls who reported participating in non-aesthetic sports but were not involved in any aesthetic sports. Hybrid participants were those girls who reported participating in both aesthetic and non-aesthetic sport types. The 
majority of participants reported participating in non-aesthetic sports only $(56 \%, \mathrm{n}=559)$, $8 \%(n=82)$ reported participating in aesthetic sports only, and $17 \%(n=166)$ reported participating in both aesthetic and non-aesthetic sports. Non-participants were those girls who did not report participating in any sporting activities $(19 \%, n=195)$.

Body Image. Measures of body image have focused primarily on the aesthetic components of the body (Smolak, 2004). This research utilizes a measure designed specifically for this study: the Embodied Image Scale (EIS; Author citation deleted. The EIS was designed to measure the multidimensional nature of body image. That is, it measures cognitive, behavioral and affective components separately, and incorporates both functional and aesthetic dimensions of the body. The goal of the measure is to compare body image from two body dimensions. Functional body image measures the extent to which adolescents value, invest in, and evaluate their bodies as a functional tool - that is, what the body can "do." Aesthetic body image (appearance oriented) measures the extent to which the body is valued, invested in and evaluated as an "aesthetic object." The scale consists of 17 items measuring 6 subscales (see appendix A); functional values (3 items), functional behavioralinvestment (3 items), functional satisfaction (3 items), aesthetic values (3 items), aesthetic behavioral-investment ( 2 items), and aesthetic satisfaction ( 3 items). The scale has demonstrated adequate internal consistency in both male and female Australian adolescents (Author citation deleted). In the current sample, the internal consistency of the EIS subscales was found to be adequate, with Cronbach's alpha levels ranging from .70-.92.

The values and aesthetic values subscales measure body values, or the extent to which adolescents value either the functional or aesthetic qualities of their bodies. For example "One of the most important reasons why people should take care of their bodies is so they can be physically active" (functional value) and "one of the most important reasons why people should take care of their bodies is so they can look good" (aesthetic value). The 
behavioral-investment subscales measure an individual's behaviors or investment in either the participant's functional or aesthetic body respectively. For example "I always try to physically challenge myself during physical activities" (functional investment) and "I always try to look the best I can" (aesthetic investment). The satisfaction subscales measure the affective or evaluative aspects of body image and ask participants to rate satisfaction with the functional and aesthetic aspects of their bodies separately. For example "I feel really good about what I can do physically" (functional satisfaction) and "I am very happy with the appearance of my body" (appearance satisfaction). Participants were asked to rate how true each body image statement was to them on a 5-point Likert scale (1=not at all true for me, $5=$ very true for me). Participants were given a mean score for each subscale. Higher scores on the EIS subscales represent a higher value of, investment in and satisfaction with the corresponding dimension of the body (functional/aesthetic).

\section{Procedure}

All year 9 and 11 students who participated in wave 1 of YAPS-WA were invited to participate in wave 2 . In schools where wave 1 student numbers were low, additional year 9 and 11 students were invited to participate in wave 2 via the distribution of parent consent forms. Participants were surveyed during classes designated by each school. The survey was administered via laptop computers connected wirelessly to a portable server. When the school could not accommodate the laptop computer setup, the survey was administered in paper and pencil format. Questions on the paper format were identical to those on the laptop survey.

\section{Results}

\section{Sports Participation and Physical Activity}

Sports participation. Seventy-nine percent $(n=791)$ of the sample reported participating in sporting activities. The most popular school-based sports were netball (38\%), soccer (17\%), volleyball (7\%), rowing $(6 \%)$ and dance $(5 \%)$. The most popular community- 
based sports were netball (26\%), basketball (10\%), soccer (9\%) and swimming (7\%).

Participants who reported participating sports activities for more than 50 hours per week were excluded from analyses $(N=3)$ as this was considered unlikely to be possible in combination with school and family commitments. Participants who reported participating in more than 10 sports in the past year (after removing sports reported as "not currently active") were also excluded from the analyses $(N=4)$ as this was considered a likely exaggeration. The final sports participant sample consisted of 743 participants. Total sport breadth ranged from 1 to 11 sports with a mean of 2.0 sports $(S D=2.08)$. Current sports breadth ranged from 0 to 10 sports with a mean of 2.0 sports $(S D=2.03)$. Participation intensity ranged from 1 to 49 hours per week with a mean of 9.3 hours per week $(S D=7.67)$.

General physical activity. Of those girls who did not participate in any sporting activities $(n=211), 38 \%(n=81)$ did not report participating in any form of physical activity (categorized as not physically active) and 62\% $(n=130)$ reported participating in some form of general physical activity (categorized as general physical activity participants).

Participants involved in general physical activity reported spending between 1 and 30 hours $(M=2.4, S D=3.21)$ per week in such activities. The most common physical activities reported were walking (22\%), exercising at home (16\%), going to the gym (14\%) and running/jogging (12\%).

Analyses of BMI, Pubertal Timing and Age as Potential Covariates

Differences in BMI data reporting among portfolios. As mentioned previously, a proportion of the sample (12\%) did not provide adequate data to calculate BMI. To establish whether the distribution of participants with BMI data and missing BMI data differed among sports portfolios, Chi-Squared tests were conducted for each portfolio group. First, the proportions of missing BMI data among girls categorized as sports participants, general physical activity participants or not physically active were compared using crosstabs. 
Seventeen percent of sports participants, $12 \%$ of general physical activity participants, and $9 \%$ of the non-physically active had missing BMI data. Girls in different physical activity portfolios were not significantly different in their provision of BMI data $\chi^{2}(2)=3.03, p=.22$, $V=.05$. Girls categorized as either aesthetic sport only, non-aesthetic sport only, hybrid participants or non-participants were then compared. Thirteen percent of aesthetic only, $12 \%$ of non-aesthetic only, $13 \%$ of hybrid participants, and $12 \%$ of non-participants had missing BMI data. Girls in these sport portfolios were also not significantly different in their provision of BMI data $\chi^{2}(3)=0.20, p=.98, V=.01$.

BMI, pubertal timing and age. To assess the potential need to include BMI, pubertal timing, and age as covariates in between-groups analyses, two separate ANOVAs were performed for both the physical activity and sports portfolios. When the physical activity portfolio (sports participants, non-participants and general physical activity participants) were examined, age differed significantly among participation groups $F(2,866)=10.96, p<.001$, partial $\eta 2=.02$ (see Table 1 ). When pairwise comparisons were made, girls who were physically active only were significantly older than both sports participants and those who were not physically active. No significant differences in BMI $F(2,866)=1.12, p=.33$, partial $\eta 2=.01$, or pubertal timing $F(2,866)=1.57, p=.21$, partial $\eta 2=.01$, were found among groups.

When the sport type portfolio (aesthetic only, non-aesthetic only, hybrid and nonparticipants) was examined, we noted significant differences in age $F(3,865)=10.47, p<$ .001 , partial $\eta 2=.01$. When pairwise comparisons were made, non-participants were significantly older than both non-aesthetic only and hybrid participants. Hybrid participants were significantly younger than all other sport types. No significant differences in BMI $F$ (3, $865)=.92, p=.43$, partial $\eta 2=.01$, or pubertal timing $F(3,865)=0.86, p=.46$, partial $\eta 2=$ 
.01 were found (see Table 2). As a result of these findings, age was included as a covariate for between-group analyses comparing both participation and sport type portfolios, whereas BMI and pubertal timing were not.

Body Image and Physical Activity Portfolios: Sports Participation, Physical Activity and No Physical Activity

To investigate differences in the six EIS subscales among sports participants, girls engaged in general physical activity and girls who were not physically active, a one-way MANCOVA was conducted, controlling for age. The results revealed a significant omnibus test, $F(12,1978)=18.32$, Wilks' criterion $=0.81, \mathrm{p}<.001$, partial $\eta 2=.10$ indicating that the physical activity portfolios differed significantly in body image. Follow-up univariate analyses indicated a significant difference in aesthetic values $F(2,994)=3.05, p<.05$, partial $\eta 2=.01$, aesthetic behavioral-investment $F(2,994)=6.50, p<.01$, partial $\eta 2=.01$, functional values $F(2,994)=14.73, p<.001$, partial $\eta 2=.03$, functional behavioralinvestment $F(2,994)=94.31, p<.001$, partial $\eta 2=.16$, and functional satisfaction $F(2$, $994)=49.05, p<.001$, partial $\eta 2=.09$ among girls in different participation portfolios (see Table 1). No significant differences in aesthetic satisfaction were found $F(2,994)=49.05, p$ $<.001$, partial $\eta 2=.09$

Post Hoc analyses (Least Significant Difference; LSD) were used to establish the significant contrasts. Aesthetic values and aesthetic behavioral-investment were both significantly lower in non-physically active girls than in sports participants. Consistent with our predictions $1 a, 1 b, 1 c$ (partially) and $1 d$, sports participants reported significantly higher functional values, functional behavioral-investment and functional satisfaction than girls who were not physically active and girls who participated in general physical activity. The 
functional values and behavioral-investment of physically active girls were significantly higher than those for girls who were not physically active (see Table 1); this was also consistent with our predictions $1 a$ and $1 b$.

Body Image and Sport Portfolios; Aesthetic Only, Non-Aesthetic Only, Hybrid Sports Participants, and Non-Participants

To investigate differences in the EIS subscales among girls participating in different sport portfolios (aesthetic sports only, non-aesthetic sports only, both aesthetic and nonaesthetic sports and non-participants), a MANCOVA was conducted, controlling for age. The results revealed a significant omnibus test, $F(18,2794)=10.48, \mathrm{p}<.001$, Wilks' criterion $=$ 0.83 , partial $\eta^{2}=.06$ indicating that the sport portfolios were significantly different in body image. Follow-up univariate analyses found no significant differences in the aesthetic values $F(3,993)=2.34, p=.07$, partial $\eta 2=.01$, or aesthetic satisfaction $F(3,993)=2.02, p=.11$, partial $\eta 2=.01$, between girls in different sport portfolios. However, significant difference were found between aesthetic behavioral-investment $F(3,993)=2.93, p<.05$, partial $\eta 2=$ .01 , functional values $F(3,993)=8.82, p<.001$, partial $\eta 2=.03$, functional behavioralinvestment $F(3,993)=53.76, p<.001$, partial $\eta 2=.14$, and functional satisfaction $F(3$, $993)=32.67, p<.001$, partial $\eta 2=.09($ see Table 2$)$.

Post Hoc analyses (LSD) were used to establish the significant contrasts. Aesthetic behavioral-investment was significantly lower in non-participants than in both aesthetic sports only participants and hybrid participants. Functional values were significantly lower in non-participants than in both non-aesthetic sport-only participants and hybrid participants. Functional behavioral-investment, and functional satisfaction were significantly lower in nonparticipants in comparison to all sport portfolios. Aesthetic sports only participants reported 
significantly lower functional behavioral-investment than both non-aesthetic only and hybrid sports participants. Non-aesthetic sports only participants reported significantly more functional satisfaction than did girls participating in aesthetic sports only (see Table 2). These findings are partially consistent with our hypotheses $2 b$ and $2 c$. However, contrary to hypothesis $2 a$, no significant differences were found in aesthetic body image between aesthetic only, non-aesthetic only and hybrid participants.

\section{Discussion}

The current study explored body image in female sports and physical activity participants. Girls were categorized into physical activity and sport type portfolios in order to investigate sports participation, physical activity, and the sporting context. Physical activity portfolios examined body image differences between sports participants, general physical activity (going to the gym, walking, jogging etc.) participants, and the non-physically active. Females participating in sports had a higher functional body image than both physically active and non-physically active girls, reporting a higher value of, behavioral-investment in, and greater satisfaction with the functional dimension of the body. In examining the sport type portfolios, we investigated body image differences between girls participating in different sport types by comparing participation in aesthetic sports only, non-aesthetic sports only, hybrid participation (both aesthetic and non-aesthetic) and non-participation. Different body image patterns emerged for girls participating in different sport contexts, with sports participants again reporting a more favorable functional body image than did non-participants.

\section{Physical Activity Portfolios and Body Image}

As hypothesized, girls involved in either sports or physical activity held a body image that incorporated the functional dimension of the body to a greater extent than sedentary girls. However, participation in sports appears to be distinct from participation in physical activity. 
Although participation in either sports or physical activity was associated with greater valuing of and behavioral-investment into the functional body than being sedentary, sports participants valued and invested in the functional body to a greater extent than did physically active girls. Sports participants were also more satisfied with their functional bodies than both physically active and non-physically active girls.

These results suggest that participation in organized sports activities may be distinct from being physically active in other settings and may offer girls a unique experience compared to other forms of physical activity. Although participation in general physical activity allows girls to experience their body instrumentally, our results suggest that being physically active (going to the gym, exercising, running, etc.) was not associated with positive evaluations regarding the body's functionality. This is consistent with previous findings where, in comparison to participation in physical activity, participation in sporting activities is associated with greater athletic competence (Ference \& Muth, 2004) and a more positive body image (Jaffe \& Lutter, 1995). Our results suggest that perceiving the body as physically competent or being satisfied with the way one's body functions may be contingent on other additional factors, such as focused cooperation and shared functional goals, rather than purely on valuing and investing in the functional qualities of the body.

General physical activity and exercise are often individual pursuits and may be undertaken as a quest to improve physical fitness and health; however appearance-related motives are also prominent in the initiation of such participation (Furnham et al., 2002; Strelan et al., 2003; Tiggemann \& Williamson, 2000). Appearance-based motives (such as weight reduction, body tone) for exercise have been associated with lower body satisfaction and body esteem (Pritchard \& Tiggemann, 2008; Strelan et al., 2003). In the current sample, the most common types of activity reported by general physical activity participants were exercising at home or going to the gym. Girls in the current sample may have held more 
appearance-based rather than functionally-based motives for their non-sport physical activity and as a result focused on improving the body's appearance rather than its physical function. However, participants' motives for exercise were not measured and this therefore remains a potential avenue for future research to explore.

Participation in sports and physical activity may not only be driven by different motives, they also occur in different environments. Where physical activities such as going to the gym are often undertaken individually, sports activities generally require the participant to be a member of a team or club. Acceptance of the body by others has been associated with a focus on body function and body acceptance (Avalos \& Tylka, 2006), and peer acceptance has been found to mediate the link between sports participation and positive self-esteem (Daniels \& Leaper, 2006). Thus the acceptance of peers may be a contributing factor to the association between sports and functional body satisfaction found in this study. However, factors associated with team versus individual pursuits were not measured in the current study, and thus such relationships are only speculative. Future research is needed to better understand the link between body image and sports participation by investigating factors such as peer acceptance and the role of peers as potential targets for body comparisons.

\section{Sport Type Portfolios and Body Image}

In order to investigate whether different sport types were related to more positive functional body image than others, the sporting context was further explored. Sports were categorized as aesthetic or non-aesthetic and girls were placed into portfolios based upon their participation in different sports (aesthetic only, non-aesthetic only and hybrid). When body image was compared across sport type portfolios, different body image patterns emerged. Overall, our results suggest that involvement in any type of sporting activity was associated with a higher functional body image than was non-participation. Non-participants were less invested in the functional body compared to girls who reported participating in any 
type of sport. Girls who participated in a non-aesthetic sport placed higher emphasis or value on their bodies' functionality than did girls who did not participate in any sport. This held true whether the sports participation was exclusively non-aesthetic or a combination of both aesthetic and non-aesthetic. Non-participants also reported being the least satisfied with their bodies' functionality. In addition, when compared with girls who participated primarily in aesthetic sports, or in a mixture of both aesthetic and non-aesthetic sports, non-participants reported lower investment in the appearance of the body.

When sport types were examined, girls involved in sports with a non-aesthetic focus reported a body image that incorporated the functional dimension of the body to a greater extent than girls involved exclusively in a sport with an aesthetic focus. Girls involved in non-aesthetic sports (alone or in combination with an aesthetic sport) also reported higher behavioral-investment and satisfaction in their bodies' functionality than girls involved exclusively in aesthetic sports, supporting our hypotheses. Previous research has identified aesthetic sports as being associated with higher emphasis on the body's appearance and less focus on the body's functionality (Parson \& Betz, 2001; Tiggemann \& Slater, 2001). We hypothesized that girls involved exclusively in aesthetic sports would report higher value and investment in the appearance of the body. Contrary to our hypotheses, girls involved in aesthetic and/or team sports did not differ from each other in their aesthetic values or behavioral-investment. Contrary to our hypotheses, we did not find significant differences in aesthetic or functional values between aesthetic only and non-aesthetic only sports participants. In addition, different sports types were also not significantly associated with differences in girls' appearance satisfaction, contrary to previous research that found variable associations with body satisfaction (Smolak et al., 2000). Conflicting body ideals have previously been reported by female sports participants, particularly as they move between the sporting and social contexts (Krane, Michelnok, \& Stiles-Shipley, 2001; Russell, 2004). 
Whereas the strong athletic body is viewed as an ideal body in the sporting context, this body is not aligned with the feminine ideal of Western society (Russell, 2004). Thus although the focus of the body within the sporting contexts is predominantly functionally based, dominant appearance ideals may still filter into such contexts and influence girls' body perceptions.

\section{Strengths and Limitations}

A large sample of Australian adolescents participated in the current study, and this is considered a major strength of this research. Participants were drawn from 34 government and non-government high schools across Western Australia from both metropolitan and rural districts, increasing the generalizability of the above findings to similar adolescent populations. However, due to ethical obligations, only students who gained parental consent and gave personal consent participated in the study, potentially resulting in a sample with more positive characteristics (reliable, with engaged parents) being overrepresented in the study. In addition, YAPS was introduced as a study of adolescent extracurricular activity participation and perhaps as a result a large proportion (79\%) of our sample reported being involved in sporting activities. Although this number appears large in comparison to international research, it is comparable with data collected by the Australian Bureau of Statistics which found that $72 \%$ of Australian females aged 14 years (2006), 64\% of aged 1214 years (2009a), and 72\% aged 15-17 years (2009b) were involved in sports or dance activities. The mean age of our participants was 14.6, falling in between the two aforementioned age groups. However, it may be that adolescents who were not involved in extracurricular activities were less motivated to participate in the study resulting in an overrepresentation of active girls, which may be viewed as a potential limitation of the current study.

Body image has been associated with BMI, pubertal timing and age variations and thus these variables were also explored within our analyses. BMI data was calculated using 
self-reported height and weight data, which have been found to correlate with objectively measured height and weight (Goodman, Hinden \& Khandelwal, 2000). However, these findings are not always consistent (Hill \& Roberts, 1998) and therefore the self-report of such measures may introduce bias, specifically if participants consistently over- or underestimated their height and weight resulting in skewed data. It is important to note that many of the participants availed themselves of the scale and height chart provided on the day of the survey, and the research team helped them to measure and then record their numbers. Some students chose not to measure themselves, and therefore not all participants provided adequate data to calculate BMI. However, when missing data were compared between portfolios, no significant differences in the provision of BMI were found, and the BMI of participants did not differ significantly among portfolios.

The current study used cross-sectional data and, as a result, selection effects may be operating. A lower physical self-worth has been associated with decreased physical activity in adolescents (Knowles, Niven, Fawkner \& Henretty, 2009) and thus girls's sports participation may be the result of, rather than the source of, functional body perceptions. Girls who initially hold high functional body values may choose to play sports and therefore sports may be viewed as a context that reinforces and maintains an already functionallyfocused body image rather than encouraging or building one. Future research should address this limitation by using longitudinal data to compare the body image of girls who continue to participate in sports, to those who join or drop out of a sporting club, or continue to be nonparticipators over the research period.

\section{Implications}

During adolescent social interactions, the appearance of the body can be discussed, compared and scrutinized (Jones, Vigfusdottir, \& Lee, 2004). However, the sporting context may offer girls an opportunity to talk about, compare and evaluate the body on the basis of 
physical skill (Russell, 2004). Although functional body image in the current study was more pronounced for girls participating in sports and physical activity, our results also illustrated that sports and physical activity participation were associated with higher valuation of the body's attractiveness and higher investment in the body's appearance, particularly when sports were aesthetically focused. These results suggest that appearance-based body ideals socialized within Western society may not be highly influenced by the functionally-based ideals found in sports and that a focus on the functional body does not necessarily replace an aesthetic focus, but may be incorporated in the strengthening of a functional body image.

Our findings suggest that the relationship between body image and sports participation is a complex one and future investigations into this relationship should take into account the type of sport in which individuals participating. Different sporting activities may encourage girls to focus on different qualities of their bodies. For example, a non-aesthetic sport such as soccer may require functional skills such as physical endurance, co-ordination and accuracy, whereas an aesthetic sport such as gymnastics may be focused on functional skills such as flexibility and strength in addition to aesthetic qualities such as leanness and body appearance. Although all sports types were associated with higher investment in the functional body compared to non-participation, participants in a combination of aesthetic and non-aesthetic sports reported a more eclectic body image than girls in other sport types. That is, girls involved in both gymnastics and soccer may be viewed as having a body image that draws positively on both aesthetic and functional body perceptions.

In order to further understand the contributions of different sport types to body image it may be fruitful to investigate the experiences girls have with their bodies during different sports activities. That is, do some sports offer girls more experiences of physical competence than others? And are aesthetic or objectified messages about the body more salient during 
certain sports? Future research could include such questions when investigating the influence of sports participation on body image, in order to capture the complexity of the relationship.

Our findings suggest that dominant cultural values may be difficult to ignore and that the functional body values taken from the sporting context may not act to replace those socialized by Western society, but are perhaps integrated into one's body image. Appearance ideals and the need to be physically attractive are salient in adolescent girls' body image. However, participation in sports activities may encourage girls to form an additional instrumental relationship with their bodies. Exploring and valuing this relationship can introduce girls to a body that is valued and invested in instrumentally (Tiggemann, 2001), reconnecting girls with the importance of functionality, and potentially leading to positive body evaluations (Gusella et al., 2004). Although participation within a sporting context may be advantageous to adolescent girls' body image, being immersed within the sporting context may not override socialization of the appearance ideals dominant in Western cultures. The sporting context may present an additional functional perspective that girls can incorporate into their body images and potentially dilute the negative effects that a focus on form may have on girls' well-being.

Focusing primarily on the aesthetic qualities of the body encourages girls to view their bodies from an outside observer's perspective (Frederickson \& Roberts, 1997), whereas focusing on the body's function may encourage girls to incorporate their experiences of physical competence when making evaluative judgements about the body. Education and service providers (such as high school teachers and intervention program developers) who aim to improve body image in adolescent female populations may wish to consider emphasizing the functional aspects of the female body to girls. Although focusing on purely aesthetic qualities of the body, and challenging preconceptions of what is beautiful, creates a more realistic ideal, this approach continues to socialize girls to view the body as an aesthetic 
object. Incorporating activities into programs that allow girls to view and experience the body instrumentally might encourage girls to understand that the female body is more than an aesthetic object and learn to value and invest in their own bodies for their functionality. 


\section{References}

Abbott, B. D., \& Barber, B. L. (2007). Not just idle time: Adolescents' developmental experiences provided by structured and unstructured leisure activities. The Australian Educational and Developmental Psychologist, 24(1), 59-81.

Australian Bureau of Statistics (ABS). (2009a). Sports and Physical Recreation: A Statistical Overview. Retrieved September 6, 2010, from

http://www.ausstats.abs.gov.au/Ausstats/subscriber.nsf/0/0EB56B94A3C69254C A25765700162698/\$File/41560_2009.pdf

Australian Bureau of Statistics (ABS). (2009b). Children's Participation in Cultural and Leisure Activities. Retrieved September 6, 2010, from http://www.ausstats.abs.gov.au/Ausstats/subscriber.nsf/0/691D5CEBE88905BCC A25765C0019E8D2/\$File/49010_Apr\% 202009.pdf

Australian Bureau of Statistics (ABS). (2006). Children's Participation in Cultural and Leisure Activities. Retrieved September 1, 2009, from http://www.ausstats.abs.gov.au/ausstats/subscriber.nsf/0/4767CFCBCB66F4DEC A2572440078021A/\$File/49010_apr\%202006.pdf

Avalos, L. C., \& Tylka, T. L. (2006). Exploring a model of intuitive eating with college women. Journal of Counseling Psychology, 53(4), 486-497.

Barker, E. T., \& Galambos, N. L. (2003). Body dissatisfaction of adolescent girls and boys: risks and resource factors. Journal of Early Adolescence, 23(2), 141-165.

Brady, M. (2005). Letting girls play: Using sport to create safe spaces and build social assets. New York: Population Council. 
Brady, M. (1998). Laying the foundation for girls' healthy futures: can sports play a role? Studies in Family Planning, 29(1), 79-82.

Brown, T. A., Cash, T. F., \& Milulka, P. J. (1990). Attitudinal body-image assessment: Factor analysis of the Body-Self Relations Questionnaire. Journal of Personality Assessment, 55(1/2), 135-144.

Burgess, G., Grogan, S., \& Burwitz, L. (2006). Effects of a 6-week aerobic dance intervention on body image and physical self-perceptions in adolescent girls. Body Image, 3, 57-66.

Cash, T. F., \& Deagle, E. A. (1997). The nature and extent of body-image disturbance in anorexia nervosa and bulimia nervosa: A meta-analysis. International Journal of Eating Disorders, 22, 107-125.

Cash, T. F., Fleming, E. C., Alindogan, J., Steadman, L., \& Whitehead, A. (2002). Beyond body image as a trait: the development and validation of the body image states scales. Eating Disorders, 10, 103-113.

Cash, T. F., Melnyk, S. E., \& Hrabosky, J. I. (2004). The assessment of body image investment: An extensive revision of the appearance schemas inventory. International Journal of Eating Disorders, 35(3), 305-316.

Clay, D., Vignoles, V. L., \& Dittmar, H. (2005). Body image and self-esteem among adolescent girls: Testing the influence of sociocultural factors. Journal of Research on Adolescence, 15(4), 451-477.

Daniels, E., \& Leaper, C. (2006). A longitudinal Investigation of sport participation, peer acceptance, and self esteem among adolescent girls and boys. Sex Roles, 55, 875-880.

Davison, T. E., \& McCabe, M. P. (2006). Adolescent body image and psychosocial functioning. Journal of Social Psychology, 146(1), 15-30. 
Ference, R., \& Muth, D. K. (2004). Helping middle school females form a sense of self through team sports and exercise. Women in Sport \& Physical Activity Journal, 13(1), 28-35.

Franzoi, S. L. (1995). The body-as-object versus the body-as-process: Gender differences and gender considerations. Sex Roles, 33(5/6), 417-437.

Franzoi, S. L., \& Shields, S. A. (1984). The body esteem scale: multidimensional structure and sex differences in a college population. Journal of Personality Assessment, 48(2), 173-178.

Fredrickson, B. L., \& Roberts, T. (1997). Objectification theory: Toward understanding women's lived experiences and mental health risks. Psychology of Women Quarterly, 21, 173-206.

Furnham, A., Badmin, N., \& Sneade, I. (2002). Body image dissatisfaction: gender differences in eating attitudes, self-esteem, and reasons for exercise. The Journal of Psychology, 136(6), 581-596.

Gadbois, S., \& Bowker, A. (2007). Gender differences in the relationship between extracurricular activities participation, self-description, and domain specific and general self-esteem. Sex Roles, 56, 675-689.

Goodman, E., Hinden, B. R., \& Khandelwal, S. (2000). Accuracy of teen and parental reports of obesity and body mass index. Pediatrics, 106(1), 52-58.

Greenleaf, C., Boyer, E. M., \& Petrie, T. A. (2009). High school sport participation and subsequent psychological well-being and physical activity: The mediating influence of body image, physical competence, and instrumentality. Sex Roles, 61(9-10), 714726. 
Gusella, J., Clark, S., \& van Roosmalen, E. (2004). Body image self-evaluation colouring lens: Comparing the ornamental and instrumental views of adolescent girls with eating disorders. European Eating Disorders Review, 12, 223-229.

Hausenblas, H. A., \& Symons Downs, D. (2001). Comparison of body image between athletes and non-athletes: A meta-analytic review. Journal of Applied Sport Psychology, 13, 323-339.

Henry, R. N., Anshel, M. H., \& Michael, T. (2006). Effects of aerobic and circuit training on fitness and body image among women. Journal of Sport Behavior, 29(4), 281-303.

Hill, A., \& Roberts, J. (1998). Body mass index: a comparison between self-reported and measured height and weight. Journal of Public Health Medicine, 20(2), 206-210.

Jaffe, L., \& Lutter, J. M. (1995). Adolescent girls: Factors influencing low and high body image. Melpomene Journal, 14(2), 14-22.

Jaffe, L., \& Manzer, R. (1992). Girls' perspectives: physical activity and self-esteem. Melpomene Journal, 11(3), 14-23.

Jaffe, L., \& Ricker, S. (1993). Physical activity and self-esteem in girls: the teen years. Melpomene Journal, 12(3), 19-26.

Jones, D. C., Vigfusdottir, T. H., \& Lee, Y. (2004). Body image and the appearance culture among adolescent girls and boys: An examination of friend conversations, peer criticism, appearance magazines, and the internalization of appearance ideals. Journal of Adolescent Research, 19, 323-339.

Kitchen, E. N. (2006). The Negotiation of Gender and Athleticism by Women Athletes. Unpublished masters thesis, Georgia State University, Atlanta.

Knowles, A., Niven, A. G., Fawkner, S. G., \& Henretty, J. M. (2009). A longitudinal examination of the influence of maturation on physical self-perceptions and the 
relationships with physical activity in early adolescent girls. Journal of Adolescence, 32, 555-566.

Krane, V. W., Michelnok, J., \& Stiles-Shipley, J. (2001). Body image concerns in female exercisers and athletes: a feminist cultural studies perspective. Women in Sport \& Physical Activity Journal, 10(1), 17-33.

Marsh, H. W., \& Jackson, S. A. (1986). Multidimensional self-concepts, masculinity, and femininity as a function of women's involvement in athletics. Sex Roles, 15(7/8), 391415.

Mckinley, N. M. (1998). Gender differences in undergraduates' body esteem: The mediating effect of objectified body consciousness and actual/ideal weight discrepancy. Sex Roles, 39(1/2), 113-123.

McKinley, N. M., \& Hyde, J. S. (1996). The objectified body consciousness scale: Development and validation. Psychology of Women Quarterly, 20, 181-215.

Mission Australia. (2008). National Survey of Young Australians 2008: Key and Emerging Issues. Retrieved February 26, 2009 from http://www.missionaustralia.com.au/document-downloads/cat_view/67-youth-surveys

Muth, J. L., \& Cash, T. F. (1997). Body image attitudes: What difference does gender make? Journal of Applied Social Psychology, 27(16), 1438-1452.

Noles, S. W., Cash, T. F., \& Winstead, B. A. (1985). Body image, physical attractiveness, and depression. Journal of Consulting and Clinical Psychology, 53(1), 88-94.

Parsons, E. M., \& Betz, N. E. (2001). The relationship of participation in sports and physical activity to body objectification, instrumentality, and locus of control among young women. Psychology of Women Quarterly, 25, 209-222. 
Paxton, S. J., Eisenberg, M. E., \& Neumark-Sztainer, D. (2006). Prospective predictors of body dissatisfaction in adolescent girls and boys: a five-year longitudinal study. Developmental Psychology, 42(5), 888-899.

Pritchard, I., \& Tiggemann, M. (2008). Relations among exercise type, self-objectification, and body image in the fitness centre environment: The role of reasons for exercise. Psychology of Sport \& Exercise, 9(6), 855-866.

Rieder, S., \& Ruderman, A. (2001). Cognitive factors associated with binge and purge eating behaviours: The interaction of body dissatisfaction and body image importance. Cognitive Therapy and Research, 25(6), 801-812.

Rierdan, J., \& Koff, E. (1997). Weight, weight-related aspects of body image and depression in early adolescent girls. Journal of Adolescent Health, 18(4), 286-291.

Rierdan, J., Koff, E., \& Stubbs, M. L. (1989). Timing of menarche, preparation, and initial menstrual experience: Replication and further analyses in a prospective study. Journal of Youth and Adolescence 18(5), 413-426.

Rosenblum, G. D., \& Lewis, M. (1999). The relations among body image, physical attractiveness, and body mass in adolescence. Child Development, 70(1), 50-64.

Russell, K. M. (2004). On versus off the pitch: the transiency of body satisfaction among female rugby players, cricketers, and netballers. Sex Roles, 51(9/10), 561-574.

Scott, B. A., \& Derry, J. A. (2005). Women in their bodies: Challenging objectification through experiential learning. Women's Studies Quarterly, 33(1/2), 188-209.

Slater, A., \& Tiggemann, M. (In Press). Gender differences in adolescent sports participation, teasing, self-objectification and body image concerns. Journal of Adolescence.

Smolak, L. (2004). Body image in children and adolescents: where do we go from here? Body Image, 1, 15-28. 
Smolak, L., Murnen, S. K., \& Ruble, A. E. (2000). Female athletes and eating problems: A meta-analysis. International Journal of Eating Disorders, 27, 371-380.

Stice, E., \& Whitenton, K. (2002). Risk factors for body dissatisfaction in adolescent girls: A longitudinal investigation. Developmental Psychology, 38(5), 669-678.

Strelan, P., Mehaffey, S. J., \& Tiggemann, M. (2003). Self-objectification and esteem in young women: the mediating role of reasons for exercise. Sex Roles, 48(1/2), 89-95.

Thompson, A. M., \& Chad, K. E. (2000). The relationship of pubertal status to body image, social physique anxiety, preoccupation with weight and nutritional status in young females. Canadian Journal of Public Health, 93(3), 207-211.

Tiggemann, M. (2001). The impact of adolescent girls' life concerns and leisure activities on body dissatisfaction, disordered eating, and self-esteem. The Journal of Genetic Psychology, 162(2), 133-142.

Tiggemann, M., \& Slater, A. (2001). A test of objectification theory in former dancers and non-dancers. Psychology of Women Quarterly, 25, 57-64.

Tiggemann, M., \& Williamson, S. (2000). The effect of exercise on body satisfaction and self-esteem as a function of gender and age. Sex Roles, 43(1/2), 119-127.

Tylka, T. L. \& Hill, M. S. (2004). Objectification theory as it relates to disordered eating among college women. Sex Roles, 51(11-12), 719-730.

Williams, P. A., \& Cash, T. F. (2001). Effects of a circuit weight training program on the body images of college students. International Journal of Eating Disorders, 30, 7582. 


\section{Appendix A}

\section{List of In-School and Out-of-School Sports Given to Participants}

\section{In-School Sports}

Athletics

Basketball

Cricket

Cycling

Football (AFL)

Hockey

Netball

Rugby

Soccer

Softball

Swimming/Diving

Tennis

Touch Rugby

Volleyball

\section{Out-of-School Sports}

\author{
Athletics \\ Baseball \\ Basketball \\ BMX (bike riding) \\ Body Boarding \\ Boxing \\ Cricket \\ Cycling \\ Football (AFL) \\ Golf \\ Gymnastics \\ Hockey \\ Horse riding/Pony Club \\ Karate/Taekwondo \\ Netball \\ Rugby \\ Soccer \\ Squash \\ Surfing \\ Swimming/Diving \\ Tennis \\ Touch Rugby \\ Volleyball
}

Note. Sports in italics are classified as aesthetic sports; dance, cheerleading and aerobics team were not listed but were reported in the other section and were also classed as an aesthetic sport. 


\section{Appendix B}

Embodied Image Scale: Subscales and Items

Subscale Items

Aesthetic Values

Aesthetic Behavioral-Investment

Aesthetic Satisfaction

Functional Values

Functional Behavioral-Investment

Functional Satisfaction
1-How good I feel about my body depends a lot on how I look

5- How good I feel about my body depends a lot on whether people consider me good-lookinga

9- One of the most important reasons why people should take care of their bodies is so they can look gooda

13-I always try to look the best I can

11- I wear certain things to make myself look as attractive as I can

7- I feel really good about the way I look

15- I am very happy with the appearance of my body

17- Overall I am very satisfied with my appearance

12- How good I feel about my body depends a lot on what my body can do physicallya

16- One of the most important reasons why people should take care of their bodies is so they can be physically active ${ }^{a}$

19- One of the most important reasons why people should take care of their bodies is so they can feel good about their physical abilities (e.g. strength, fitness, endurance)

2- I do physically active things often ${ }^{c}$ (e.g.; sports, hiking, exercise)

6- I always try to physically challenge myself during physical activities

8- I participate in physical activities whenever I can (e.g.; sports, hiking, exercise)

14- I feel really good about what I can do physicallyc

18- I am very happy with my performance in physical activities

10- Overall I am very satisfied with my physical abilities

Note. The number next to each item represents the order of presentation; items 3 and 4 are missing as these were the items removed as a result of factor analyses (Abbott \& Barber, 2010)

${ }^{\mathrm{a}}=$ Modified from Lehman and Koerner, 2004.

${ }^{\mathrm{b}}=$ Taken directly from Lehman and Koerner, 2004.

${ }^{c}=$ Modified from the Physical Self-Description Questionnaire - short format, (Peart, Marsh \& Richards, 2005). 


\section{Research Highlights}

- Sports and physical activity participants reported differing body image

- Functional body image was highest among sports participants

- Body image differed between aesthetic and non-aesthetic sport types 
Table 1.

Descriptive Statistics for Values, Investment, and Satisfaction with the Functional and Aesthetic Body Dimensions Among Female Sports Participants, General Physical Activity Participants and Non-Participants

\begin{tabular}{|c|c|c|c|}
\hline & $\begin{array}{c}\text { Sports Participant } \\
(n=738) \\
\text { Mean }(S D)\end{array}$ & $\begin{array}{c}\text { Physically Active } \\
(n=84) \\
\text { Mean }(S D)\end{array}$ & $\begin{array}{c}\text { Non-Physically Active } \\
(n=77) \\
\text { Mean }(S D)\end{array}$ \\
\hline Aesthetic Values & $3.1^{\mathrm{a}}(0.98)$ & $3.1^{\mathrm{a}, \mathrm{b}}(1.04)$ & $2.8^{\mathrm{b}}(1.06)$ \\
\hline Aesthetic Behavioral-Investment & $3.4^{\mathrm{a}}(1.00)$ & $3.4^{\mathrm{a}}(1.08)$ & $2.9^{\mathrm{b}}(1.08)$ \\
\hline Aesthetic Satisfaction & $3.1(1.00)$ & $3.0(1.00)$ & $2.9(1.07)$ \\
\hline Functional Values & $3.4^{\mathrm{a}}(0.82)$ & $3.1^{\mathrm{b}}(0.82)$ & $2.9^{c}(0.94)$ \\
\hline Functional Behavioral- Investment & $3.7^{\mathrm{a}}(0.90)$ & $3.1^{\mathrm{b}}(0.94)$ & $2.4^{\mathrm{c}}(0.97)$ \\
\hline Functional Satisfaction & $3.6^{\mathrm{a}}(0.89)$ & $2.9^{\mathrm{b}}(0.98)$ & $2.7^{\mathrm{b}}(0.95)$ \\
\hline Age & $14.6^{\mathrm{a}}(1.08)$ & $15.1^{\mathrm{b}}(1.07)$ & $14.7^{\mathrm{a}}(1.06)$ \\
\hline Pubertal Timing & $3.0(0.89)$ & $3.0(0.92)$ & $2.8(0.76)$ \\
\hline BMI & $20.6(3.85)$ & $21.2(3.63)$ & $20.8(4.18)$ \\
\hline
\end{tabular}

Note. EIS sub-scale range 1-5. Means that do not share superscripts are significantly different at .05 alpha level. Pubertal Timing scale range 1-5. 
Table 2.

Descriptive Statistics for Values, Investment, and Satisfaction with the Functional and Aesthetic Body Dimensions Among Females with

Different Sports Profiles and Non-Participants

\begin{tabular}{|c|c|c|c|c|}
\hline & $\begin{array}{l}\text { Aesthetic Sport Only } \\
(n=57) \\
\text { Mean }(S D)\end{array}$ & $\begin{array}{l}\text { Non-Aesthetic Sport } \\
\text { Only }(n=492) \\
\text { Mean }(S D)\end{array}$ & $\begin{array}{l}\text { Hybrid (Aesthetic and } \\
\text { Non-Aesthetic) } \\
(n=189) \\
\text { Mean }(S D)\end{array}$ & $\begin{array}{l}\text { Non-Participants } \\
(n=161) \\
\text { Mean }(S D)\end{array}$ \\
\hline Aesthetic Values & $3.1(0.86)$ & $3.0(1.0)$ & $3.2(0.98)$ & $3.0(1.07)$ \\
\hline Aesthetic Behavioral-Investment & $3.5^{\mathrm{a}}(0.87)$ & $3.3^{\mathrm{a}, \mathrm{b}}(1.03)$ & $3.5^{\mathrm{a}}(0.95)$ & $3.2^{\mathrm{b}}(1.10)$ \\
\hline Aesthetic Satisfaction & $3.2(0.79)$ & $3.1(1.02)$ & $3.1(0.99)$ & $2.9(1.04)$ \\
\hline Functional Values & $3.2^{\mathrm{a}, \mathrm{b}}(0.75)$ & $3.4^{\mathrm{a}}(0.85)$ & $3.4^{\mathrm{a}}(0.76)$ & $3.0^{\mathrm{b}}(0.88)$ \\
\hline Functional Behavioral- Investment & $3.4^{\mathrm{a}}(0.91)$ & $3.7^{\mathrm{b}}(0.9$ & $3.8^{\mathrm{b}}(0.83)$ & $2.8^{\mathrm{c}}(1.01)$ \\
\hline Functional Satisfaction & $3.3^{\mathrm{a}}(0.83)$ & $3.6^{\mathrm{b}}(0.93)$ & $3.6^{\mathrm{a}, \mathrm{b}}(0.78)$ & $2.8^{\mathrm{c}}(0.98)$ \\
\hline Pubertal Timing & $2.9(0.76)$ & $3.0(0.91)$ & $3.1(0.90)$ & $3.0(0.87)$ \\
\hline BMI & $20.4(3.16)$ & $20.7(4.17)$ & $20.4(2.80)$ & $21.0(3.90)$ \\
\hline
\end{tabular}

Note. EIS sub-scale range 1-5. Means that do not share superscripts are significantly different at .05 alpha level. Pubertal Timing scale range 1-5. 